

\title{
Sustainability analysis of French dietary guidelines using multiple criteria
}

Emmanuelle Kesse-Guyot, Dan Chaltiel, Juhui Wang, Philippe Pointereau, Brigitte Langevin, Benjamin Allès, Pauline Rebouillat, Denis Lairon, Rodolphe Vidal, François Mariotti, et al.

\section{To cite this version:}

Emmanuelle Kesse-Guyot, Dan Chaltiel, Juhui Wang, Philippe Pointereau, Brigitte Langevin, et al.. Sustainability analysis of French dietary guidelines using multiple criteria. Nature Sustainability, 2020, 3 (5), pp.377-385. 10.1038/s41893-020-0495-8 . hal-02912151

\section{HAL Id: hal-02912151 \\ https://hal.science/hal-02912151}

Submitted on 17 May 2021

HAL is a multi-disciplinary open access archive for the deposit and dissemination of scientific research documents, whether they are published or not. The documents may come from teaching and research institutions in France or abroad, or from public or private research centers.
L'archive ouverte pluridisciplinaire HAL, est destinée au dépôt et à la diffusion de documents scientifiques de niveau recherche, publiés ou non, émanant des établissements d'enseignement et de recherche français ou étrangers, des laboratoires publics ou privés. 
Sustainability analysis of French dietary guidelines using multiple criteria

Emmanuelle Kesse-Guyot ${ }^{1}$, Dan Chaltiel ${ }^{1 *}$, Juhui Wang $^{2} *$, Philippe Pointereau ${ }^{3}$, Brigitte Langevin $^{3}$, Benjamin Allès ${ }^{1}$, Pauline Rebouillat ${ }^{1}$, Denis Lairon ${ }^{4}$, Rodolphe Vidal ${ }^{5}$, François Mariotti $^{2}$, Manon Egnell ${ }^{1}$, Mathilde Touvier ${ }^{1}$, Chantal Julia ${ }^{1,6}$, Julia Baudry ${ }^{1}$, Serge Hercberg ${ }^{1,6}$

*Authors contributed equally to the article

${ }^{1}$ Université Paris 13, CRESS - EREN (Nutritional Epidemiology Research Team) INSERM, INRA, CNAM, 74 rue Marcel Cachin, 93017 Bobigny, France

${ }^{2}$ UMR PNCA, AgroParisTech, INRA, Université Paris-Saclay, 75005, Paris, France

${ }^{3}$ Solagro, 75, Voie TOEC, CS 27608, F-31076 Toulouse Cedex 3, France

${ }^{4}$ Aix Marseille Université, INSERM, INRA, C2VN, 13005 Marseille, France

${ }^{5}$ Institut Technique de l'Agriculture Biologique (ITAB), 75595 Paris, France

${ }^{6}$ Département de Santé Publique, Hôpital Avicenne, 93017 Bobigny, France

Correspondance: Email: e.kesse@eren.smbh.univ-paris13.fr

Equipe de Recherche en Epidémiologie Nutritionnelle (EREN)

SMBH Université Paris 13, 74 rue Marcel Cachin, 93017 Bobigny, France

Running title: sustainability of dietary guidelines

Keywords: dietary guidelines, diet sustainability, environment-related indicators, pesticides

PubMed indexing: Kesse-Guyot, Chaltiel, Wang, Pointereau, Langevin, Allès, Rebouillat, Lairon, Vidal, Mariotti, Egnell, Touvier, Baudry, Hercberg

Number of tables: 1/Number of figures: 4/Supplemental information: 2 Method, 7 Tables. 


\section{$1 \quad$ Abstract}

2 Sustainability is now accounted in some Food-Based Dietary Guidelines (FBDG). In 2017, the French

3 FBDG were updated and incorporated environmental preservation. We conduct a multi-indicator 4 evaluation of the 2001 and 2017 FBDG, based on data from 28,240 participants of the NutriNet-Santé 5 cohort, completing an organic food frequency questionnaire. Indicators related to nutrition, 6 environment ( 3 indicators and the synthetic pReCiPe score) and economy are used distinguishing 7 organic and conventional farming systems. To estimate compliance with the 2001 and 2017 FBDG, 8 we used two validated adherence scores (PNNS-GS1 and PNNS-GS2, respectively). We estimated 9 numbers of averted deaths by adhering to the FBDG using a Competing Risk Assessment model. 10 Higher adherence to the 2017 guidelines was related to higher plant-based diet, cost and death averted 11 and lower energy intake, lower synthetic environmental score and lower exposure to some pesticides. 12 Overall, larger differences between lowest versus highest PNNS-GS2 were observed than between 13 lowest versus highest PNNS-GS1. Our results suggest that the 2017 guidelines are overall in line with 14 the multiple dimensions of diet sustainability, including health, although at a slight cost increase. If 15 adopted by a large part of the population, these dietary guidelines may contribute to prevent chronic 16 diseases while reducing food-related environmental pressures. 
In developed countries, western diets are characterized by high intake of sugar, salt, saturated fat and meat, together with extensive consumption of highly processed food, raising major health and environmental concerns ${ }^{1}$. As diet is a major determinant of various non-communicable diseases ${ }^{2}$, official food-based dietary guidelines have been developed and disseminated since the 1950's by governments to promote healthy diets ${ }^{3}$.

Beyond health consequences for individuals, current food systems, from farm to fork, are responsible for about one quarter to one third of Greenhouse Gas emissions (GHGE) and cause major risks in terms of soil, and water pollution and biodiversity loss ${ }^{1}$. This has led to the definition of a sustainable diet as "protective and respectful of biodiversity and ecosystems, culturally acceptable, accessible, economically fair, and affordable, nutritionally adequate, safe, and healthy, while optimizing natural and human resources" ${ }^{4}$. Recent 2050 's projections suggest that unsustainable dietary patterns rich in meat and processed food may lead to an increase in GHGE up to $80 \%$ from the current baseline ${ }^{5}$. Therefore, changing food production, processing, and distribution as well as dietary patterns may lead to substantial reductions in GHGE and may overall improve the sustainability of the diet ${ }^{6}$.

For instance, some plant-based dietary patterns such as the Mediterranean or vegetarian diets which exhibit noticeable beneficial effects on health have been recognized as more respectful of the environment and are considered as a model of sustainable diet ${ }^{1,7,8}$. Promoting shifts toward more plant-based diets, as advised by the Food-based Dietary Guidelines (FBDG), may contribute to reduce both GHGE and morbidity/mortality related to dietary factors ${ }^{1,9-11}$. A recent report pointed out that the establishment of official dietary guidelines are crucial actions for nutrition policy and education. Thus, they could embrace sustainability by encouraging people to consume plant-based diets ${ }^{12}$.

There is a substantial and growing body of evidence supporting the development of integrated dietary approaches to align both long term health and sustainability dimensions ${ }^{13}$. However, only few countries have developed official food-based dietary guidelines including sustainability as a major policy issue ${ }^{14}$. Historically, this concept is not recent as Joan Dye Gussow for the first time proposed dietary guidelines including sustainability-related dimensions in $1986{ }^{15}$.

In France, the first food-based dietary guidelines were implemented in 2001 within the framework of the French Nutrition and Health Program (PNNS). The guidelines for the adult population have been 
extensively modified in 2017 and now emphasize the need for alignment between health and environmental dimensions of the diet ${ }^{16}$. Important modifications have been introduced in 2017 FBDG compared to the 2001 FBDG. Briefly, legumes, red and processed meat have been individualized and adequation cut-offs have been lowered for milk and dairy products, seafood and alcohol intake. Nut intake has also been added and added fat now focused on alpha-linolenic acid rich oils (as canola and walnut oil) and olive oil. Favoring consumption of organic plant foods is now advised as a precautionary principle to limit exposure to pesticides. Of note, weights have been allocated to the different components. To assess the health benefits for individuals to follow these recommendations, we have previously developed and validated two a priori dietary indexes, reflecting the level of adherence to the 2001 and 2017 national dietary guidelines, namely two versions of the PNNSguidelines scores (PNNS-GS1 and PNNS-GS2, respectively) ${ }^{17,18}$.

We evaluate the associations between various indicators reflecting the dimensions of diet sustainability (nutrition, environment, economic and sanitary aspects) and long-term health impacts (death avoided), and different levels of adherence to the 2017 FBDG. With regard to nutritional aspects, the indicators encompassed the PANDiet score for overarching nutrient adequacy, contribution of organic food to the intake, energy intake and energy density. The following indicators, GHGE, cumulative energy demand, land occupation expressed environmental pressure while pReCiPe expressed overall environmental impact. The cost of the diet as well as exposure to pesticides were also included as economic and sanitary indicators. It should be noted that pressure indicators are different from impact indicators, as they inform users on the pressure human activities place on ecosystems (e.g., the land used to produce a crop) rather than on the potential consequences (impact) due to such pressure ${ }^{19}$. They quantify either resource use or pollution, or both. A second objective is to compare these associations with those found when using the 2001 FBDG. To meet these objectives, we conducted a multi-criteria analysis among a large sample of participants of the French NutriNetSanté cohort, based on nutritional, environmental, economic and toxicological indicators.

\section{Results}


The sample included $75.6 \%$ women and mean age was $49.9 \mathrm{y} \pm 15.9$. Means of PNNS-GS2 were 2.41 $(\mathrm{SD}=3.35)$ and $0.63(\mathrm{SD}=3.75)$ for women and men, respectively, while means of PNNS-GS1 were $8.27(\mathrm{SD}=1.86)$ and $8.31(\mathrm{SD}=1.62)$ for women and men, respectively.

Sample characteristics. Characteristics of the study population are presented in Table 1. Participants with higher PNNS-GS2 (reflecting higher adherence to the 2017 FBDG) had more often higher educational level and monthly household income than individuals with lower PNSS-GS2. They exhibited more often high level of physical activity, a lower body mass index and were more likely to be non-smokers and with a managerial staff or intellectual profession compared to individuals with lower PNSS-GS2.

Food consumptions. Food group consumptions across quintiles (Q) of PNNS-GS2 are presented in Supplementary Table 1. As expected by its construction, higher PNNS-GS2 was associated with higher consumption of fruit and vegetables, legumes and whole grains but also soya-based food, and lower consumption of seafood, meat, poultry, processed meat and dairy products, sweetened foods and fast-food, alcoholic and non-alcoholic beverages and fats. For comparison, food group consumptions across quintiles of PNNS-GS1 are shown in Supplementary Table 2.

The association between indicators of diet sustainability and adherence to 2001 and 2017 FBDG are presented in Supplementary Table 3 and relative difference are shown in Figure 1.

Nutritional aspects. The total weight of the diet, the proportion of organic food in the diet and the PANDiet (reflecting the probability of adequacy to nutrient references) were positively associated with the level of adherence, whatever the FBDG score studied. As expected by its construction, the increase of the share of organic food in the diet between Q1 and Q5 was stronger for PNNS-GS2 than for PNNS-GS1 quintiles. Lower energy intake and energy density were related to higher adherence to both FBDG scores.

Environmental aspects. After adjustment for energy intake, lower diet-related environmental pressure and impacts were associated with higher level of adherence for both scores (except energy demand for the PNNS-GS1), however the decreases observed across quintiles were much greater with 
PNNS-GS2. For the $p$ ReCiPe comprising GHGE, energy use and land occupation, a decrease of about 25\% was observed for PNNS-GS1 and of 50\% for PNNS-GS2.

Economical aspects. Finally, the cost of the diet was positively associated with PNNS-GS2 and PNNS-GS1 but the magnitude of the increase between Q1 and Q5 was smaller for PNNS-GS2. Differences between Q5 and Q1 were $0.91 € / \mathrm{d}$ and $1.29 € / \mathrm{d}$ for PNNS-GS2 and PNNS-GS1, respectively.

Overall, larger differences between Q1 and Q5 for the studied indicators were observed for PNNSGS2 in comparison with PNNS-GS1 (Figure 1).

Pesticides exposure aspects. Correlations (factor loadings) between exposure to individual pesticides and exposure profiles extracted by non-negative matrix factorization (NMF) are presented in Supplementary Table 4. The first NMF-factor was highly positively correlated with exposure to imazalil, profenofos and chlorpyriphos while the second one was positively correlated with exposure to spinosad (mostly used in organic but also in conventional production). The third one was positively correlated with exposure to acetamiprid, carbendazim, chlorpyriphos and dimethoate.

Relative difference in NMF-extracted scores between Q5 and Q1 for PNNS-GS1 and PNNS-GS2 are graphically presented in Figure 2. Higher PNNS-GS2 was associated with lower scores for the first and third NMF-extracted factors (relative differences Q5 vs. Q1<0). As regards the PNNS-GS1, a positive association was observed with the first NMF-extracted factor (relative differences Q5 vs. Q1>0) and no difference for the NMF-extracted factor 3 was detected. Higher PNNS-GS2 was associated with higher NMF-extracted factor 2. A similar but less strong positive association was observed for the PNNS-GS1.

Health aspects. Predicted numbers of death averted or delayed (overall and by causes) related to higher PNNS-GS2, as compared to lower PNNS-GS2, and higher PNNS-GS1, are presented in Figures 3 and 4. High adherence to 2017 FBDG led to 35,689 predicted averted premature deaths, mostly cardiovascular diseases. When comparing high level (Q5) of PNNS-GS2 to high level of PNNS-GS1, 3,408 deaths were averted or delayed, with some variations depending on the disease. The diseases most affected were heart failure and hypertensive disease, bronchus tract and lung cancer. On 
124 the other hand, a high compliance with the 2001 FBDG prevented an additional small number of

125 bronchus and lung cancers compared to high compliance with the 2017 FBDG.

\section{Discussion}

127 This study made it possible to examine the link between compliance with official French dietary 128 recommendations and sustainability through a wide range of indicators covering nutritional, 129 environmental, economic and health dimensions. Indeed, in this large cohort of French adults, we 130 observed that high adherence to the 2017 FBDG leads to a more sustainable diet than not following the guidelines. Environmental pressure indicators related to dietary patterns were drastically lower among participants with high (vs. low) adherence to the 2017 dietary guidelines. In addition, high adherence to the 2017 FBDG leads to much more sustainability than high adherence to the 2001 recommendations. Overall, the number of averted or delayed deaths by adhering to 2017 was higher than adhering to the 2001 FBDG. However, taking into consideration current market prices, higher level of adherence to the 2017 FBDG diet was associated with higher diet cost. Interestingly, diet costs of participants with high adherence to 2001 FBDG was higher than those of participants with high adherence to 2017 FBDG.

These findings are important in terms of public health as they lend credence to the view that there are co-benefits of aligning dietary recommendations for both health promotion and environment preservation, in the urgent context of climate change. These results provide evidence that 2017 FBDG, designed in line with sustainability considerations, effectively meet this objective.

Nutritional indicators. It should be noted that the association with the PANDiet, expressing the overall adequacy to nutrient references, was very similar between PNNS-GS1 and PNNS-GS2 despite the limitation of animal-product consumption in the 2017 FBDG. This indicates that the recent modifications in dietary recommendations do not appear to affect the overall nutritional adequacy of the diet also sub-score of components differed (Supplementary Table 3). It is also noteworthy that adhering to the 2017 FBDG was negatively associated with energy intake and energy density which are risk factors for obesity ${ }^{20}$.

150 Environmental. Our findings could be interpreted in light of differences in dietary patterns across the 151 different levels of adherence to FBDG. Indeed, the 2017 FBDG promote low consumption of animal 
152 products, including the moderation of dairy product consumption and limitation of red meat and

153 processed meat product intake. These lower intakes of animal-based products in Q5 are clearly 154 responsible for the much lower levels of dietary GHGE compared to Q1 ${ }^{1,21}$. Despite somewhat lower 155 yields in organic farming ${ }^{22,23}$, land occupation was lower for high $v s$. low adherence to these 156 guidelines. This can be explained by the more plant-based diet among participants following the 2017 157 FBDG. This association was negative, even after adjustment for energy intake. Lower GHGE and land 158 occupation were also related to higher PNNS-GS1, however, the magnitude of the decrease between 159 Q1 and Q5 was smaller for PNNS-GS1. In addition, due to the recommendation of lower pesticides 160 adherence, by including organic food, adherence to 2017 FBDG could also contribute to biodiversity 161 preservation ${ }^{24}$. Based on French representative dietary surveys ${ }^{25}$, and dietary data on our population ${ }^{26}$, it can be postulated that dietary patterns of individuals in Q1 in our study population are close to those of the general French population. In our study, we observed that reaching the highest adherence to the 2017 FBDG (as observed in Q5) would imply a 50\% reduction in global environmental impacts (estimated by the pReCiPe) and specifically a $46 \%$ reduction in GHGE (when comparing Q5 to Q1) but would require major changes in current French dietary patterns. In order to specifically focus on differences in diet composition for fixed energy intake, the associations were estimated using energy intake adjustment. Indeed, as a strong decrease in daily energy intake was observed across quintiles of adherence, all links would have been driven by the role of energy intake. For instance, without energy adjustment, relative differences between high and low adherence to 2017 FBDG (Q5 vs. Q1 of PNNSGS2) were $-24.0 \%$ and $-63.1 \%$ for dietary cost and GHGE respectively (Supplementary Table 5), while they were $+12.9 \%$ and $-46.6 \%$ respectively for adjusted parameters.

Economic. As regards economic aspects, adhering to the 2017 FBDG was related to a higher cost, after adjustment for energy intake. However, this increase was small (less than $1 € / d)$. Healthier products which are more expensive ${ }^{27}$ may explain the higher dietary monetary cost of adherence. In addition, organic foods are generally more expensive than conventional foods, due to more extensive

177 practices, lower productivity, higher labor cost or higher farmer's income in organic production ${ }^{28}$. The 178 slightly increased cost, in an isocaloric diet, of the new food-based guidelines may be of concern for 
180 Exposure to pesticides. Consumption of organic plant-food as promoted in the 2017 FBDG

181 contributed to a lower exposure to some pesticide residues whereas promoting fruit and vegetable 182 consumption without promoting organic food (2001 FBDG) would lead to a higher exposure. A lower 183 bound scenario was used, which tends to underestimate the exposure. However, this scenario was 184 selected considering that organic foods contain far lower synthetic pesticides residues compared with 185 conventional foods ${ }^{29}$.

186 Health. We also showed, using the EpiDiet model, that high adherence to 2017 FBDG would lead to 187 an important predicted number of averted or delayed deaths (about 35,689 for year 2014). A large part 188 of the averted or delayed deaths were cardiovascular diseases. These results are consistent with the current epidemiological scientific literature about dietary prevention of cardiovascular diseases and cancer ${ }^{30,31}$, indicating a beneficial role of dietary patterns rich in fruit and vegetables, nuts, whole191 grains and fish and a harmful role of red meat, processed meat and sugar-sweetened beverages. These 192 food groups have been specifically emphasized in the 2017 FBDG. Moreover, in line with our present findings, we previously observed in two different French cohorts, that higher PNNS-GS (based on 2001 FBDG, and including physical activity) was prospectively inversely associated with cardiovascular diseases and cancer risk ${ }^{32-34}$. The adherence to the 2017 FBDG, compared to the 2001 FBDG, allowed to prevent or delay a substantial number of deaths. It should also be born in mind that number of deaths for some health events was underestimated by the EpiDiet model. This model indeed only accounts for nutritional values of the diet. Indeed, specific other components, such as synthetic pesticide residues or other contaminants such as heavy metals contained in fish are not taken into account. An important component not considering in the model was pesticide exposure now accounted for in the 2017 FBDG. Diet based on organic food has indeed been linked with a reduction in overall cancer risk by our team ${ }^{35}$ and in specific cancer site risk by others ${ }^{36}$.

203 Sustainability. The potential agreement between healthy and environment-friendly diets has recently 204 been extensively documented ${ }^{1,5,11,37-40}$. For instance, a modeling study concluded that changes toward more plant-based diets (at least 5 portions/d of fruit and vegetables) would reduce overall mortality by 
${ }^{11}$. Also Tilman and Clark, through a modeling study have estimated that following a plant-based diet (vegetarian, pescetarian or Mediterranean diets) may reduce all-cause mortality rates from $0 \%$ to $18 \%$ and GHGE from 30 to $55 \%{ }^{5}$.

Recently, a growing number of countries have integrated sustainability or environmental values in their official dietary guidelines ${ }^{41,42}$. However, few observational studies, using a multi-criteria approach, have documented the sustainable potential of following FBDGs also focusing on diet sustainability. A recent study was conducted in Spain aiming to compare environmental values of current diets, adherence to FBDG and other diet models, in particular the Mediterranean diet ${ }^{43}$. The authors found that shifting current dietary patterns to diets in line with FBDG and Mediterranean diet would lead to $17 \%$ and $11 \%$ reduction in GHGE, respectively. They also showed that food loss may contribute to $21 \%$ of these emissions. Our findings are also consistent with those of a European modelling study documenting co-benefits of meeting dietary recommendations for health and environment ${ }^{44}$.

Some limitations of our work should be highlighted. First, food consumption data were self-reported as no objective measurements to assess food consumption are available in large-scale population studies. However, the methods used in dietary surveys have been validated and organic food consumption assessed by the Org-FFQ has been previously found to be negatively associated with certain pesticide residues in urine ${ }^{45}$ and positively with some nutritional biomarkers ${ }^{46}$. Second, the NutriNet-Santé cohort included volunteers, who were probably more concerned by health and diet than general population. While a weighting procedure was applied, a selection bias limiting extrapolation to the general population may remain. Third, there is a lack of data on post-farm environmental pressure for organic agriculture, thus Life Cycle Assessments were limited to farm activities. Therefore, transportation and distribution through the food system were not accounted for in the estimation of the environmental pressure. However, most environmental pressure of food generally occur at the farm level ${ }^{47,48}$. Fourth, environmental pressures were assessed for a relatively limited number of indicators. According to Kramer et al $^{49}$, the three indicators included in the pReCiPe can be considered sufficient for an acceptable representativeness of the overall environmental impact. However, there are many more relevant indicators ${ }^{19}$. For instance, in a recent study, Springman et al 
used five of them ${ }^{50}$. In particular is would be very important to consider for water use which has been previously included in a study conducted in the United Kingdom, France and Germany ${ }^{51}$. In addition, organic food consumption can be used as a proxy of biodiversity preservation ${ }^{24}$. Furthermore, as regards exposure to pesticides, some key mineral-based pesticides (for instance copper or sulfur) used in organic agriculture were not available. Finally, the EpiDiet was based on robust data from metaanalysis limiting the parametrization of the model and only accounting for nutritional effect, and morbidity was not accounted for.

Some elements should be emphasized. The large sample size covered a wide diversity of dietary patterns. The wide spectrum of accurately collected data and the use of the EpiDiet model allowed to cover a large variety of indicators related to sustainability, and to provide, for the first-time, a thorough evaluation of the sustainability of the FBDG, while accounting for the farming system and other indicators rarely considered. A major strength is also the observational design of our study, as it illustrates that some segments of the population are actually able to closely follow the FBDG. Thus, following the new FBDG may contribute to health improvement and environment preservation, if largely adopted. However, there is still leeway insofar as the very high adherents exhibited only suboptimal but not optimal diet.

In conclusion, the present study provided an estimate of the sustainable values of the 2017 French FBDG, using available diet sustainability indicators. Adherence to this new FBDG aligns with virtually all sustainability metrics, apart from a slight increase in cost which should be considered by all stakeholders involved in nutrition, health and sustainability. These results therefore underline the urgent need for the development of public health strategies allowing accessibility to healthy and sustainable diets for all segments of the population. Adopted by a large part of the French population, these 2017 dietary guidelines may highly contribute to preventing diet-related chronic diseases and reduce environmental impacts, in particular by drastically reducing diet-related GHGE.

\section{Methods}

This study is based on data from the NutriNet-Santé study.

Population. The web-based prospective NutriNet-Santé a has been cohort initiated in France in May $2009{ }^{52}$. Participants are adults internet users recruited on a voluntary basis from the general French 
population. This study is conducted in accordance with the Declaration of Helsinki, and all procedures were approved by the Institutional Review Board of the French Institute for Health and Medical Research (IRB Inserm 0000388FWA00005831) and the National Commission on Informatics and Liberty (Commission Nationale de l'Informatique et des Libertés, CNIL 908450 and 909216). Electronic informed consent was obtained from all participants. The NutriNet-Santé study is registered in ClinicalTrials.gov (NCT03335644).

Dietary data. At inclusion and yearly thereafter, participants completed self-administered questionnaires inquiring about socioeconomic status, anthropometrics, lifestyle, physical activity, and dietary intakes. They were also regularly invited to fill in complementary questionnaires. The present study is based on data collected in the BioNutriNet project, an ancillary project developed within the NutriNet-Santé cohort which has been extensively described elsewhere ${ }^{22}$. Briefly, from June to December 2014, a self-administered semi-quantitative organic food frequency questionnaire (OrgFFQ), based on a validated FFQ ${ }^{53}$, was administered. The Org-FFQ includes questions on frequency and quantity of food consumed over the last 12 months, completed by a five-point ordinal scale aiming to measure the frequency of organic (under official label) food consumption for 264 items ${ }^{54}$. Participants were asked to answer the following question for food items that exist in organic 'How often was the product of organic origin?' using the following response modalities: never, rarely, halfof-time, often or always. Organic food consumption was obtained by attributing the respective percentages: $0,25,50,75$ and 100 to the modalities. Sensitivity analyses as regards the weighting have been published elsewhere ${ }^{54}$. The food and beverage items were gathered into 16 food groups as listed in Supplementary Table 1. Nutrient intake estimations were derived from a published food composition database ${ }^{55}$ for generic items independently of the farming system (organic vs. conventional).

Under-reporting and over-reporting participants were defined ${ }^{54}$ as individuals with ratio between energy intake and energy requirement below or above cutoffs previously identified $(<0.35$ and $>1.93$ were excluded). Energy requirement was estimated using basal metabolic rate (BMR) and physical activity level. BMR was estimated by Schofield equations ${ }^{56}$ depending on gender, age, weight and height. 
To assess the nutritional quality of participants' diet, a modified version of the validated PNNS-GS (without physical activity) was computed, here named PNNS-GS1 for clarity purpose. This modified score reflects the adherence to the official French nutritional recommendations set up in 2001 within

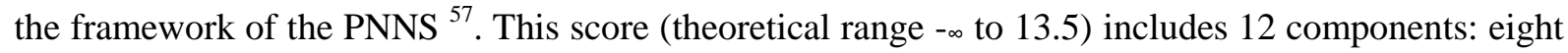
refer to food-serving adequacy recommendations (fruit and vegetables; starchy foods; whole grain products; dairy products; meat, eggs and fish; fish and seafood; vegetable fat; water $v s$. soda) and four refer to moderation in consumption (added fat; salt; sweets; alcohol). Moreover, points are deducted for overconsumption of salt, added sugars, or when energy intake exceeds the estimated energy needs by more than $5 \%$.

Recently, the PNNS-GS2 (The theoretical range was $-\infty$ to 14.25) has been developed based on the 2017 dietary guidelines and validated against sociodemographic and biological data ${ }^{18}$. Guidelines, components, scoring, and weights of both scores are detailed in Supplementary Table 6. Penalties were also applied to overconsumption. Cut-offs and scorings were built based on a consensus of experts so as 1 and 0 points were allocated for meeting and not meeting a guideline for healthy foods while 0 and -1 point were allocated for meeting and not meeting a guideline for unhealthy foods. In addition, half-points were allocated linearly to improve discrimination power between cut-offs. An exception concerned milk and dairy products as well as fish for which the relationship to global health has been found non-linear, hence a parabolic-shaped relationship in allocated points. Another holistic nutritional indicator (PANDiet) reflecting the overall probability of nutrient adequacy was computed, as previously published in full details ${ }^{58}$ to focus on nutrients intakes beyond food consumption. Briefly, this score is the mean of an adequacy score (which averages the probabilities of adequacy for 27 nutrients) and a moderation score involving six nutrients and twelve potential penalty values that combine probabilities of exceeding upper limits of intakes.

314 Environmental pressure indicators. Assessment of environmental pressure indicators in the 315 BioNutriNet project has been fully described elsewhere ${ }^{59}$. Briefly, three environmental pressure indicators were considered at the farm level (excluding conditioning, transport, processing, storage or recycling stages): the GHGE measured as $\mathrm{kg}$ of $\mathrm{CO}_{2}$ equivalents $\left(\mathrm{CO}_{2} \mathrm{eq}\right)$, the cumulative energy 
318 demand in $\mathrm{MJ}$, and the land occupation expressed in $\mathrm{m}^{2}$. Data were collected from the tool

319 DIALECTE developed by Solagro (Toulouse, France) ${ }^{60}$. The DIALECTE database aims to depict

320 French farming systems in order to evaluate the environmental performance of farms base on $>60$ raw

321 products. The original database has been completed by other data sources that have been previously

322 listed ${ }^{59}$, to obtain the environmental pressure in organic and conventional for 92 raw agricultural

323 products covering the 264 food items. A set of conversions was used to estimate environmental

324 pressure to produce food items as consumed by applying economic allocation (accounting for co-

325 products) and cooking and edibility coefficients.

326 Dietary environmental impacts per day, at the individual level, were computed by multiplying the

327 daily consumption of each food item by its respective environmental and conversion factor values, and

328 then summing up all items consumed, while differentiating the farming system (conventional or

329 organic).

330 To consider trade-offs and conflicts between environmental indicators, the ReCiPe method was

331 previously developed. This method initially developed in the Netherlands consider the alignment of

332 midpoint-oriented and endpoint-oriented indicators ${ }^{61}$. In practice, some authors showed that the

333 greenhouse gas emissions, primary energy consumption and land occupation account for

334 approximately $90 \%$ of the total environmental dimension of the ReCiPe allowing to define the partial

335 ReCiPe score (pReCiPe) for environmental impact assessment of food product and diet ${ }^{49}$.

336 The $p \operatorname{ReCiPe}$, indicator of environmental impact, was calculated for each individual:

$$
p \operatorname{ReCiPe}=[0.0459 * \mathrm{GHGE}+0.0025 * \mathrm{CED}+0.0439 * \mathrm{LO}]
$$

338 Where GHGe is greenhouse gas emissions, in $\mathrm{kgCO} 2 \mathrm{eq} / \mathrm{kg}$, CED is cumulative energy demand, in

$339 \mathrm{MJ} / \mathrm{kg}$ and LO is land occupation, in $\mathrm{m}^{2} / \mathrm{kg}$. By construction, the highest the pReCiPe is the highest is

340 the environmental impact.

341 Economic data. In 2014, places of food purchase for all food groups were collected by a specific web-based questionnaire. Food prices for each of the 264-FFQ items (organic and conventional) for

343 each place of purchase were estimated by the mean price values obtained from the 2012 Kantar

344 Worldpanel purchase database from a representative sample of 20,000 French households ${ }^{62}$. The 
database was completed by supplementary data on prices collected by the Bioconsom'acteurs association to take into account specific short supply chains.

The individual daily diet monetary cost $(€ / \mathrm{d})$ was computed by multiplying each intake of foods by the corresponding prices, while accounting for the farming system and the place of purchase, and by then summing up all daily consumed items.

Pesticide exposure. Exposure to diet-related pesticides, i.e. residues of plant protection product (PPP), was evaluated through the estimation of dietary exposure through plant food items (since they are the most contaminated foods ${ }^{29}$ ). A total of 15 active substances authorized in the EU for PPP at the date of data collection were selected, considering either their frequency of detection above the Maximum Residue Levels, when sufficient data were available, or their Acceptable Daily Intake. Contamination data were obtained from the CVUA Stuttgart (Chemisches und Veterinäruntersuchungsamt) database for 180 plant ingredients constituting of the 264 food items and available in the CVUA database ${ }^{63}$. For each active substance, the estimated daily intake (EDI) (in $\mu \mathrm{g} / \mathrm{kg}$ body weight/d) was calculated under a lower bound scenario, using the reference method described by Nougadère et al. ${ }^{64}$. EDI was used to identify pesticide dietary-exposure profiles, as previously described by Traoré et al. ${ }^{65}$, using $\mathrm{NMF}^{66}$ (Supplementary Method 1). This method aims to identify profiles combining the original variables, namely exposure to several pesticides, with a score value for each participant.

Sample selection. For the present study, we considered the participants of the NutriNet-Santé study having completed the Org-FFQ between June and December 2014 ( $\mathrm{N}=37,685)$, with no missing covariates $(\mathrm{N}=37,305)$, not detected as under- or over-energy reporter $(\mathrm{N}=35,196)$, living in mainland France to permit the computation of a weighting procedure described below $(\mathrm{N}=34,453)$, and with available data regarding the place of purchase for the computation of the dietary monetary cost, leading to a final sample of 28,340 participants.

Statistical Analyses. To improve representativeness of the sample compared to the overall French population, the study sample was weighted. For each gender, weighting was calculated using the iterative proportional fitting procedure using 2009 French national census reports ${ }^{67}$ for age, occupational category, educational level, area of residence and presence of children $(<18$ years $)$ and marital status. Participants were ranked and categorized into sex-specific weighted quintiles of dietary 
indexes reflecting the level of adherence to 2001 and 2017 food-based dietary guidelines, using the PNNS-GS1 and PNNS-GS2. Associations between food group consumption, nutritional indicators, environmental impact indicators, dietary costs and pesticide residue exposure, and quintiles of PNNSGSs were modeled with ANCOVA using observed margins and adjusted for energy intake (unless specified otherwise), providing adjusted means and $95 \%$ confidence intervals. The list and details of the sustainability indicators are presented in Supplementary Table 7. Multiple testing was accounted for by Tukey adjustment. P-values refer to P-trends estimated using linear contrasts. We used EpiDiet (Evaluate the Potential Impact of a Diet) model to evaluate the health benefits of the 2017 FBDG. EpiDiet is a simulation-based nutritional and epidemiologic model implementing the Comparative Risk Assessment framework. Like many other simulation-based risk assessment models ${ }^{68,69}$, it quantifies the positive or negative changes in risk related to long term health that would result from changes in the average diet for an individual, groups or population. In this study, we took as baseline and counterfactual situations the extreme quintiles (Q1, Q5) of PNNS-GS2, or the Q5s of PNNS-GS1 and PNNS-GS2, and estimated the health impact of changes in dietary and nutrients intake. Details of the EpiDiet model and its application are presented in Supplementary Method 2. The relative risks were obtained from data published for the PRIME model ${ }^{68}$ and a recent metaanalysis ${ }^{70}$. Two-sided tests were used and a p-value $<0.05$ was considered significant. Data management and statistical analyses were performed using SAS (version 9.4; SAS Institute, Inc., Cary, NC, USA). NMF was performed using the NMF R-package ${ }^{71}$.

\section{Correspondence and requests for materials should be addressed to Emmanuelle Kesse-Guyot}

\section{Acknowledgements}

We thank Oualid Hamza, Christine Boizot-Santai, Louis-Georges Soler and Bioconsom'acteurs' members for price collection and data management, the CVUAS for the pesticide residue database and Noémie Soton for her contribution to the data management of the CVUA database. We also thank Cédric Agaesse (dietitian); Thi Hong Van Duong, Younes Esseddik (IT manager), Régis Gatibelza, Djamal Lamri, Jagatjit Mohinder and Aladi Timera (computer scientists); Julien Allegre, Nathalie Arnault, Laurent Bourhis and Fabien Szabo de Edelenyi, $\mathrm{PhD}$ (supervisor) (data-manager/statisticians) 
400 for their technical contribution to the NutriNet-Santé study and Nathalie Druesne-Pecollo, PhD

401 (operational coordination). We thank all the volunteers of the NutriNet-Sante cohort.

402 The authors' contributions are as follows:

403 EKG, BA, MT, CJ and SH conducted the study.

404 EKG, PP, BL, RV, DL, and JB conducted the research and implemented databases.

405 JW and FM conducted the EPIDiet simulation

406 EKG performed statistical analyses and drafted the manuscript.

407 All authors critically helped in the interpretation of results, revised the manuscript and provided

408 relevant intellectual input. They all read and approved the final manuscript.

409 EKG had primary responsibility for the final content, she is the guarantor.

410 Conflict of Interest

411 No author declared conflict of interest.

\section{Transparency statement}

413 Dr Kesse-Guyot (the guarantor) affirms that the manuscript is an honest, accurate, and

414 transparent account of the study being reported; that no important aspects of the study have

415 been omitted; and that any discrepancies from the study as planned have been explained.

416 Data availability statement: Data can be retrieved from the corresponding author upon

417 reasonable request

418 Code availability statement: Code and programs can be retrieved from the corresponding

419 author upon reasonable request.

$420 \quad$ Funding

421 The NutriNet-Santé study is funded by French Ministry of Health and Social Affairs, Santé Publique

422 France, Institut National de la Santé et de la Recherche Médicale, Institut National de la Recherche Agronomique, Conservatoire National des Arts et Métiers, and Paris 13 University. The BioNutriNet

424 project was supported by the French National Research Agency (Agence Nationale de la Recherche)

425 in the context of the 2013 Programme de Recherche Systèmes Alimentaires Durables (ANR-13-ALID- 
426 0001). The funders had no role in the study design, data collection, analysis, interpretation of data, 427 preparation of the manuscript, and decision to submit the paper. 


\section{References}

1. Willett, W. et al. Food in the Anthropocene: the EAT-Lancet Commission on healthy diets from sustainable food systems. Lancet 393, 447-492 (2019) doi:10.1016/S0140-6736(18)31788-4.

2. Joint WHO-FAO Expert Consultation on Diet, N., and the Prevention of Chronic Diseases. Diet, nutrition, and the prevention of chronic diseases: report of a WHO-FAO Expert Consultation ; [Joint WHO-FAO Expert Consultation on Diet, Nutrition, and the Prevention of Chronic Diseases, 2002, Geneva, Switzerland]. (World Health Organization, 2003).

3. Mozaffarian, D., Rosenberg, I. \& Uauy, R. History of modern nutrition science-implications for current research, dietary guidelines, and food policy. BMJ 361, k2392 (2018) doi:10.1136/bmj.k2392.

4. Burlingame, B. \& Dernini, S. Sustainable diets and Biodiversity. in vol. Proceedings of FAO International Scientific Symposium Sustainable diets and Biodiversity united against hunger, Roma, November 3-5, 2010 (FAO Edition, Rome, 2012).

5. Tilman, D. \& Clark, M. Global diets link environmental sustainability and human health. Nature 515, 518-522 (2014) doi:10.1038/nature13959.

6. Garnett, T. Where are the best opportunities for reducing greenhouse gas emissions in the food system (including the food chain)? Food Policy 36, S23-S32 (2011) doi:10.1016/j.foodpol.2010.10.010.

7. Burlingame, B. \& Dernini, S. Sustainable diets: the Mediterranean diet as an example. Public Health Nutr. 14, 2285-2287 (2011) doi:10.1017/S1368980011002527.

8. Sofi, F., Macchi, C., Abbate, R., Gensini, G. F. \& Casini, A. Mediterranean diet and health status: an updated meta-analysis and a proposal for a literature-based adherence score. Public Health Nutr. 17, 2769-2782 (2014) doi:10.1017/S1368980013003169.

9. Lindgren, E. et al. Sustainable food systems-a health perspective. Sustain Sci 13, 1505-1517 (2018) doi:10.1007/s11625-018-0586-X.

10. Meybeck, A., Redfern, S., Paoletti, F. \& Strassner, C. Assessing sustainable diets within the sustainability of food systems. Mediterranean diet, organic food: new challenges. in vol. 
Proceedings of an International Workshop (FAO, CREA, FQH), 15-16 September 2014 (Rome: Food and Agriculture Organization, 2014).

11. Springmann, M., Godfray, H. C. J., Rayner, M. \& Scarborough, P. Analysis and valuation of the health and climate change cobenefits of dietary change. PNAS 113, 4146-4151 (2016) doi:10.1073/pnas.1523119113.

12. Swinburn, B. A. et al. The Global Syndemic of Obesity, Undernutrition, and Climate Change: The Lancet Commission report. The Lancet 393, 791-846 (2019) doi:10.1016/S0140-6736(18)328228.

13. Tuomisto, H. L. Importance of considering environmental sustainability in dietary guidelines. Lancet Planet Health 2, e331-e332 (2018) doi:10.1016/S2542-5196(18)30174-8.

14. Lang, T. \& Mason, P. Sustainable diet policy development: implications of multi-criteria and other approaches, 2008-2017. Proceedings of the Nutrition Society 77, 331-346 (2018) doi:10.1017/S0029665117004074.

15. Gussow, J. D. \& Clancy, K. L. Dietary guidelines for sustainability. Journal of Nutrition Education 18, 1-5 (1986) doi:10.1016/S0022-3182(86)80255-2.

16. HCSP. Statement related to the revision of the 2017-2021 French Nutrition and Health Programme's dietary guidelines for adults. https://www.hcsp.fr/explore.cgi/avisrapportsdomaine?clefr=653 (2017).

17. Estaquio, C. et al. Adherence to the French Programme National Nutrition Santé Guideline Score is associated with better nutrient intake and nutritional status. J Am Diet Assoc 109, 1031-1041 (2009) doi:10.1016/j.jada.2009.03.012.

18. Chaltiel, D. et al. Programme National Nutrition Santé - guidelines score 2 (PNNS-GS2): development and validation of a diet quality score reflecting the 2017 French dietary guidelines. British Journal of Nutrition 122, 331-342 (2019) doi:10.1017/S0007114519001181.

19. Vanham, D. et al. Environmental footprint family to address local to planetary sustainability and deliver on the SDGs. Science of The Total Environment 693, 133642 (2019) doi:10.1016/j.scitotenv.2019.133642. 
20. Blüher, M. Obesity: global epidemiology and pathogenesis. Nat Rev Endocrinol (2019) doi:10.1038/s41574-019-0176-8.

21. Poore, J. \& Nemecek, T. Reducing food's environmental impacts through producers and consumers. Science 360, 987-992 (2018) doi:10.1126/science.aaq0216.

22. Baudry, J. et al. Improvement of diet sustainability with increased level of organic food in the diet: findings from the BioNutriNet cohort. Am J Clin Nutr 109, 1173-1188 (2019) doi:10.1093/ajen/nqy361.

23. Reganold, J. P. \& Wachter, J. M. Organic agriculture in the twenty-first century. Nature Plants 2 , 15221 (2016) doi:10.1038/nplants.2015.221.

24. Gomiero, T., Pimentel, D. \& Paoletti, M. G. Environmental impact of different agricultural management practices: conventional vs. organic agriculture. Crit Rev Plant Sci. 30, 95-124 (2011).

25. Santé Publique France. Étude de santé sur l'environnement, la biosurveillance, l'activité physique et la nutrition (Esteban), 2014-2016. Volet nutrition. Chapitre consommations. http://invs.santepubliquefrance.fr/Publications-et-outils/Rapports-et-syntheses/Environnement-etsante/2017/Etude-de-sante-sur-1-environnement-la-biosurveillance-l-activite-physique-et-lanutrition-Esteban-2014-2016.

26. Baudry, J. et al. Dietary intakes and diet quality according to levels of organic food consumption by French adults: cross-sectional findings from the NutriNet-Santé Cohort Study. Public Health Nutr 20, 638-648 (2017) doi:10.1017/S1368980016002718.

27. Rao, M., Afshin, A., Singh, G. \& Mozaffarian, D. Do healthier foods and diet patterns cost more than less healthy options? A systematic review and meta-analysis. BMJ Open. 3, e004277 (2013) doi:10.1136/bmjopen-2013-004277.

28. Boizot-Szantai, C., Hamza, O. \& Soler, L.-G. Organic consumption and diet choice: An analysis based on food purchase data in France. Appetite (2017) doi:10.1016/j.appet.2017.06.003.

29. EFSA. The 2015 European Union Report on Pesticide Residues in Food. EFSA Journal, 11(3), 3130. (2017). 
30. Bechthold, A. et al. Food groups and risk of coronary heart disease, stroke and heart failure: A systematic review and dose-response meta-analysis of prospective studies. Crit Rev Food Sci Nutr 1-20 (2017) doi:10.1080/10408398.2017.1392288.

31. WCRF/AICR. Cancer preventability estimates for diet, nutrition, body fatness, and physical activity. World Cancer Research Fund https://www.wcrf.org/dietandcancer/contents (2017).

32. Kesse-Guyot, E. et al. Higher adherence to French dietary guidelines and chronic diseases in the prospective SU.VI.MAX cohort. Eur J Clin Nutr 65, 887-894 (2011) doi:10.1038/ejcn.2011.61.

33. Lavalette, C. et al. Cancer-Specific and General Nutritional Scores and Cancer Risk: Results from the Prospective NutriNet-Santé Cohort. Cancer Res. 78, 4427-4435 (2018) doi:10.1158/00085472.CAN-18-0155.

34. Assmann, K. E. et al. Dietary scores at midlife and healthy ageing in a French prospective cohort. Br. J. Nutr. 116, 666-676 (2016) doi:10.1017/S0007114516002233.

35. Baudry, J. et al. Association of Frequency of Organic Food Consumption With Cancer Risk: Findings From the NutriNet-Santé Prospective Cohort Study. JAMA Internal Medicine 178, 1597 (2018) doi:10.1001/jamainternmed.2018.4357.

36. Bradbury, K. E. et al. Organic food consumption and the incidence of cancer in a large prospective study of women in the United Kingdom. Br J Cancer 110, 2321-2326 (2014) doi:10.1038/bjc.2014.148.

37. Hallström, E., Carlsson-Kanyama, A. \& Börjesson, P. Environmental impact of dietary change: a systematic review. J Clean Prod 91, 1-11 (2016).

38. Aleksandrowicz, L., Green, R., Joy, E. J., Smith, P. \& Haines, A. The Impacts of Dietary Change on Greenhouse Gas Emissions, Land Use, Water Use, and Health: A Systematic Review. PLoS.One. 11, e0165797 (2016) doi:10.1371/journal.pone.0165797.

39. Auestad, N. \& Fulgoni, V. L., III. What current literature tells us about sustainable diets: emerging research linking dietary patterns, environmental sustainability, and economics. Adv.Nutr. 6, 19-36 (2015) doi:10.3945/an.114.005694. 
40. Perignon, M., Vieux, F., Soler, L. G., Masset, G. \& Darmon, N. Improving diet sustainability through evolution of food choices: review of epidemiological studies on the environmental impact of diets. Nutr.Rev. 75, 2-17 (2017) doi:10.1093/nutrit/nuw043.

41. European Public Health Association - EUPHA. Healthy and Sustainable Diets for European Countries.

https://eupha.org/repository/advocacy/EUPHA_report_on_healthy_and_sustainable_diets_20-052017.pdf (2017).

42. Health Canada. Canada's dietary guidelines for health professionals and policy makers. (2019).

43. Batlle-Bayer, L. et al. The Spanish Dietary Guidelines: A potential tool to reduce greenhouse gas emissions of current dietary patterns. Journal of Cleaner Production 213, 588-598 (2019).

44. Cobiac, L. J. \& Scarborough, P. Modelling the health co-benefits of sustainable diets in the UK, France, Finland, Italy and Sweden. Eur J Clin Nutr (2019) doi:10.1038/s41430-019-0401-5.

45. Baudry, J. et al. Urinary pesticide concentrations in French adults with low and high organic food consumption: results from the general population-based NutriNet-Santé. Journal of Exposure Science \& Environmental Epidemiology (2018) doi:10.1038/s41370-018-0062-9.

46. Baudry, J. et al. Some Differences in Nutritional Biomarkers are Detected Between Consumers and Nonconsumers of Organic Foods: Findings from the BioNutriNet Project. Curr Dev Nutr 3, nzy090 (2019) doi:10.1093/cdn/nzy090.

47. Clune, S., Crossi,E. \& Verghese, K. Systematic review of greenhouse gas emissions for different fresh food categories. J Clean Prod 140 (Part 2), 766-783 (2017).

48. Weidema, B. \& Meeusen, M. J. G. Agricultural Data for Life Cycle Assessments. 1-189 (2010).

49. Kramer, G. F., Tyszler, M., Veer, P. V. \& Blonk, H. Decreasing the overall environmental impact of the Dutch diet: how to find healthy and sustainable diets with limited changes. Public Health Nutr 20, 1699-1709 (2017) doi:10.1017/S1368980017000349.

50. Springmann, M. et al. Health and nutritional aspects of sustainable diet strategies and their association with environmental impacts: a global modelling analysis with country-level detail. Lancet Planet Health 2, e451-e461 (2018) doi:10.1016/S2542-5196(18)30206-7. 
51. Vanham, D., Comero, S., Gawlik, B. M. \& Bidoglio, G. The water footprint of different diets within European sub-national geographical entities. Nature Sustainability 1, 518-525 (2018) doi:10.1038/s41893-018-0133-x.

52. Hercberg, S. et al. The Nutrinet-Sante Study: a web-based prospective study on the relationship between nutrition and health and determinants of dietary patterns and nutritional status. BMC Public Health 10, 242 (2010) doi:10.1186/1471-2458-10-242.

53. Kesse-Guyot, E., Castetbon, K., Touvier, M., Hercberg, S. \& Galan, P. Relative validity and reproducibility of a food frequency questionnaire designed for French adults. Ann. Nutr. Metab. 57, 153-162 (2010) doi:10.1159/000321680.

54. Baudry, J. et al. Contribution of Organic Food to the Diet in a Large Sample of French Adults (the NutriNet-Santé Cohort Study). Nutrients 7, 8615-8632 (2015) doi:10.3390/nu7105417.

55. Etude Nutrinet-Santé. Table de composition des aliments de l'étude Nutrinet-Santé (NutrinetSanté Study Food Composition Database). Paris: Economica. (2013).

56. Schofield, W. N. Predicting basal metabolic rate, new standards and review of previous work. Hum Nutr Clin Nutr 39 Suppl 1, 5-41 (1985).

57. Hercberg, S., Chat-Yung, S. \& Chauliac, M. The French National Nutrition and Health Program: 2001-2006-2010. International Journal of Public Health 53, 68-77 (2008).

58. Gavelle, E. de, Huneau, J.-F. \& Mariotti, F. Patterns of Protein Food Intake Are Associated with Nutrient Adequacy in the General French Adult Population. Nutrients 10, (2018) doi:10.3390/nu10020226.

59. Seconda, L. et al. Comparing nutritional, economic, and environmental performances of diets according to their levels of greenhouse gas emissions. Clim. Change 148, 155-172 (2018) doi:10.1007/s10584-018-2195-1.

60. Pointereau, P., Langevin, B. \& Gimaret, M. DIALECTE, a comprehensive and quick tool to assess the agro-environmental performance of farms. in (2012).

61. Goedkoop, M. et al. ReCiPe 2008: A Life Cycle Impact Assessment Method Which Comprises Harmonised Category Indicators at the Midpoint and the Endpoint Level. 132 (2013).

62. Kantar Worldpanel. Consumer Panels. https://www.kantarworldpanel.com/global. 
63. CVUA Stuttgart. UA-BW. http://www.cvuas.de/pub/default.asp?subid=1.

64. Nougadère, A., Reninger, J.-C., Volatier, J.-L. \& Leblanc, J.-C. Chronic dietary risk characterization for pesticide residues: a ranking and scoring method integrating agricultural uses and food contamination data. Food Chem. Toxicol. 49, 1484-1510 (2011) doi:10.1016/j.fct.2011.03.024.

65. Traoré, T. et al. To which mixtures are French pregnant women mainly exposed? A combination of the second French total diet study with the EDEN and ELFE cohort studies. Food Chem. Toxicol. 111, 310-328 (2018) doi:10.1016/j.fct.2017.11.016.

66. Lee, D. D. \& Seung, H. S. Algorithms for Non-negative Matrix Factorization. in Advances in Neural Information Processing Systems 13 (eds. Leen, T. K., Dietterich, T. G. \& Tresp, V.) 556562 (MIT Press, 2001).

67. Institut National de la Statistique et des Etudes Economiques (INSEE). La macro SAS CALMAR. (2015).

68. Scarborough, P., Harrington, R. A., Mizdrak, A., Zhou, L. M. \& Doherty, A. The Preventable Risk Integrated ModEl and Its Use to Estimate the Health Impact of Public Health Policy Scenarios. Scientifica.(Cairo.) 2014, 748750 (2014) doi:10.1155/2014/748750.

69. Murray, C. J. L. \& Lopez, A. D. Measuring the global burden of disease. N. Engl. J. Med. 369, 448-457 (2013) doi:10.1056/NEJMra1201534.

70. Micha, R. et al. Association Between Dietary Factors and Mortality From Heart Disease, Stroke, and Type 2 Diabetes in the United States. JAMA 317, 912-924 (2017) doi:10.1001/jama.2017.0947.

71. Gaujoux, R. \& Seoighe, C. A flexible R package for nonnegative matrix factorization. $B M C$ Bioinformatics 11, 367 (2010) doi:10.1186/1471-2105-11-367. 


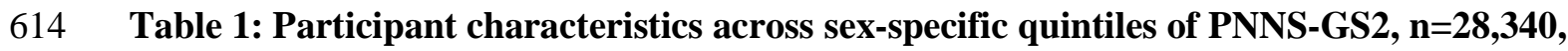

615 NutriNet-Santé, 2014 ${ }^{1}$

\begin{tabular}{|c|c|c|c|c|c|c|}
\hline & All & Q1 & $\mathbf{Q 2}$ & Q3 & Q4 & Q5 \\
\hline Non-weighted N & 28,340 & 4937 & 5550 & 5737 & 5973 & 6143 \\
\hline Cut-off in women & & $-0.22<$ & $-0.22-1.86$ & $1.86-3.53$ & $3.53-5.34$ & $>5.34$ \\
\hline Cut-off in men & & $<-2.52$ & -0.252 .52 & $-0.25-1.72$ & $1.72-3.98$ & $>3.98$ \\
\hline Age, y & $49.9 \pm 15.9$ & $48.1 \pm 0.2$ & $49.4 \pm 0.2$ & $50.1 \pm 0.2$ & $50.9 \pm 0.2$ & $51.0 \pm 0.2$ \\
\hline \multicolumn{7}{|l|}{ Education (\%) } \\
\hline$<$ High-school diploma & 44.3 & 47.3 & 43.3 & 42.9 & 43.9 & 44.3 \\
\hline High school diploma & 19.0 & 20.6 & 19.4 & 18.6 & 18.1 & 18.4 \\
\hline Postgraduate & 36.6 & 32.2 & 37.3 & 38.5 & 37.9 & 37.3 \\
\hline \multicolumn{7}{|l|}{ Occupation (\%) } \\
\hline Unemployed & 4.7 & 4.8 & 4.5 & 4.7 & 4.7 & 4.9 \\
\hline Retired & 31.7 & 27.2 & 31.2 & 32.4 & 33.6 & 34.3 \\
\hline Employee, manual worker & 22.7 & 29.3 & 24.3 & 20.4 & 20.2 & 19.2 \\
\hline Intermediate profession & 16.5 & 16.2 & 16.7 & 18.1 & 16.3 & 15.1 \\
\hline $\begin{array}{l}\text { Managerial staff and } \\
\text { intellectual profession }\end{array}$ & 12.2 & 9.4 & 11.4 & 12.7 & 14.1 & 13.4 \\
\hline Never employed & 9.5 & 10.4 & 9.4 & 9.0 & 9.0 & 9.8 \\
\hline Self-employed, farmer & 2.6 & 2.8 & 2.3 & 2.8 & 2.1 & 3.2 \\
\hline \multicolumn{7}{|l|}{ Monthly income (\%) } \\
\hline Unwilling to answer & 7.2 & 6.5 & 7.2 & 7.2 & 7.3 & 7.6 \\
\hline$<1,200 €$ & 17.8 & 22.2 & 17.5 & 15.7 & 15.4 & 18.1 \\
\hline $1,200-1,800 €$ & 28.4 & 31.1 & 30.3 & 29.3 & 26.3 & 25.1 \\
\hline $1,800-2,700 €$ & 26.7 & 24.4 & 26.2 & 26.8 & 28.8 & 27.4 \\
\hline$>2,700 €$ & 19.9 & 15.8 & 18.8 & 21.0 & 22.2 & 21.8 \\
\hline \multicolumn{7}{|l|}{ Physical activity level (\%) } \\
\hline Missing data & 12.3 & 13.1 & 13.2 & 12.3 & 11.8 & 11.2 \\
\hline Low & 19.9 & 24.7 & 22.0 & 20.4 & 18.8 & 13.8 \\
\hline Moderate & 34.6 & 32.2 & 33.0 & 35.4 & 34.8 & 37.4 \\
\hline High & 33.2 & 30.0 & 31.8 & 31.9 & 34.7 & 37.6 \\
\hline \multicolumn{7}{|l|}{ Tobacco status (\%) } \\
\hline Never smoker & 51.0 & 44.4 & 51.3 & 52.9 & 52.6 & 53.9 \\
\hline Former smoker & 37.1 & 39.2 & 36.7 & 35.0 & 37.9 & 36.9 \\
\hline Current smoker & 11.8 & 16.4 & 12.0 & 12.1 & 9.5 & 9.2 \\
\hline
\end{tabular}

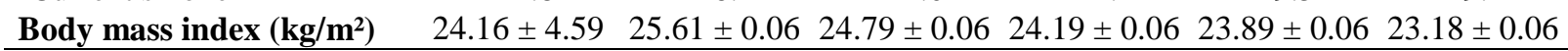

616 Abbreviations: Q= Quintile

$617{ }^{1}$ All values presented are weighted data. Values are means \pm SD or percent, as appropriate. P-values are based on

618 linear contrast test for continuous variables or chi-square test for, all P-values $<0.0001$

619 categorical variables 
620 Figure 1: Relative differences for sustainable indicators between high vs. low adherence (Q5 vs. 621 Q1) to PNNS-GS1 and PNNS-GS2 ${ }^{1,2}$

622 Abbreviations: $\mathrm{D}=$ relative difference as $(\mathrm{Q} 5-\mathrm{Q} 1) * 100 / \mathrm{Q} 1$; $\mathrm{Q}=$ Quintile

$623{ }^{1}$ Values are adjusted for energy intake (except daily kcal intake).

$624{ }^{2} \%$ for diet cost, pReCiPe, Land occupation, GHGE, energy demand, energy density and energy intake are reversed so that a positive value ( $>$ reference $=0$ in red) indicates a positive impact

Figure 2: Relative differences for dietary exposure to pesticides between high vs. low adherence (Q5 vs. Q1) to PNNS-GS1 and PNNS-GS2

Abbreviations: $\mathrm{D}=$ relative difference as $(\mathrm{Q} 5-\mathrm{Q} 1) * 100 / \mathrm{Q} 1 ; \mathrm{Q}=$ Quintile

Figure 3: Estimated number of deaths averted or delayed (year 2014) using the EpiDiet comparing high $v s$. low adherence to 2017 dietary guidelines, $n=28,340$, NutriNet-Santé, 2014 ${ }^{1}$ classified according the International Statistical Classification of Diseases and Related Health Problems $10^{\text {th }}$ Revision. comparing high adherence to 2017 dietary guidelines $v$ s. high adherence to 2001 dietary guidelines, $\mathrm{n}=\mathbf{2 8 , 3 4 0}$, NutriNet-Santé, 2014 ${ }^{1}$

${ }^{1}$ Values are estimated numbers (95\% uncertainty interval based on parameters model uncertainty) for diseases

641 classified according the International Statistical Classification of Diseases and Related Health Problems $10^{\text {th }}$

642 Revision. 